3. Федеральная служба государственной статистики «О финансовых результатах деятельности организаций в 2020 году» URL: https://gks.ru/bgd/free/B04_03/IssWWW.exe/Stg/d02/41.htm

4. Шалаева Л.В. Учет затрат и калькулирование себестоимости продукции в растениеводстве [Текст]: учебное пособие / Л.В. Шалаева - Пермь: ИПЦ «Прокростъ», 2018.

5. Шлегель Т.Ю. Особенности учета затрат на производство и калькуляция себестоимости продукции растениеводства [Текст] / Т.Ю. Шлегель - Омск: Омская гуманитарная академия, 2018.

\title{
Тарасова А.C. \\ Российский рынок ипотечного жилищного кредитования: программы поддержки населения и цифровизация банковских процессов
}

Дальневосточный федеральный университет

(Россия, Владивосток)

doi: $10.18411 / \mathrm{j}-08-2021-82$

\section{Аннотация}

Проблемы на рынке ипотечного жилищного кредитования затрагивают как потребителей, так и банки, предоставляющие данные услуги. В данной статье рассмотрены существующие программы поддержки населения на рынке ипотечного жилищного кредитования, их перспективность и результативность. Цифровизация, разработка и внедрение новых технологических решений в целях развития банковского бизнеса играет огромную роль при существующей конкуренции.

Ключевые слова: ипотека, ИЖК (ипотечное жилищное кредитование), ФинТех, онлайн-кредит, цифровизация, цифровая экономика, ВРМ-системы, программы поддержки населения.

\section{Abstract}

Problems in the housing mortgage lending market affect both consumers and banks that provide these services. This article examines the existing programs to support the population in the housing mortgage lending market, their prospects and effectiveness. Digitalization, development and implementation of new technological solutions for the development of the banking business plays a huge role in the current competition.

Keywords: mortgage, housing mortgage lending, Fintech, online credit, digitalization, digital economy, BPM systems, population support programs.

Ипотечное кредитование является активно развивающимся сектором в России на данный момент. Перед Правительством Российской Федерации стоит задача упрощение процесса кредитования населения, перевод сделок в электронный формат, учитывая пандемию и возможность заражения при офлайн встречах. Так же закрытие очных отделений позволит снизить издержки банков, сократить потраченное на оформление бумаг время.

Анализ показателя объема ипотечного жилищного кредитования (далее ИЖК) на рынке за последние 3 года.

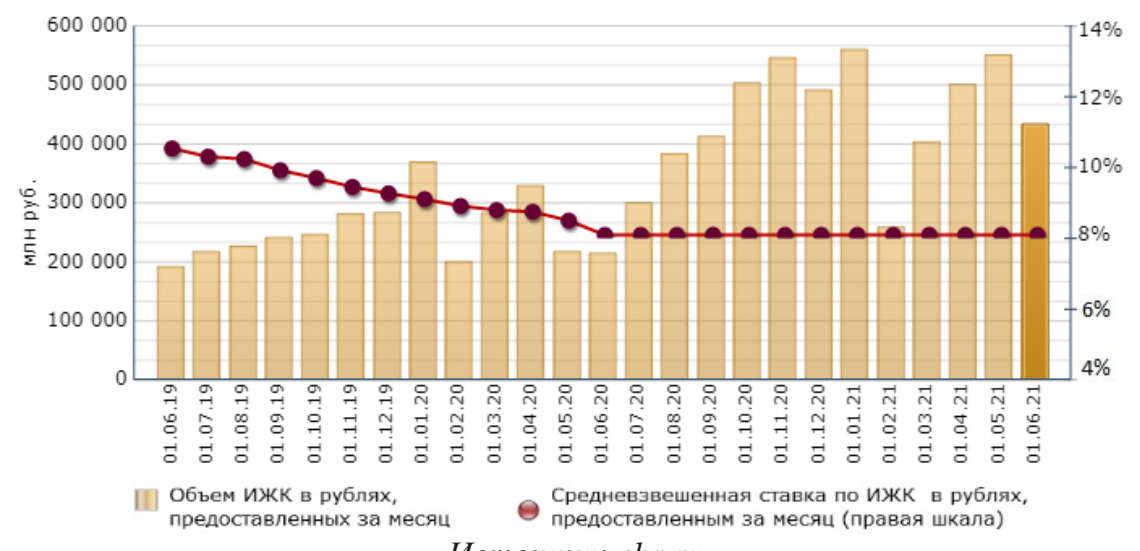

Источник: cbr.ru 
Положительные прогнозы экспертов относительно роста рынка ИЖК в 2019 г. не подтвердились на практике. Объем выдачи кредитов в 2019 году уменьшился впервые за 4 года. Кредитными организациями (далее КО) было выдано порядка 1,3 млн кредитов на сумму 2,8 трлн руб., что на 14 \% меньше по сравнению с показателями 2018 года (3 трлн руб.). В целом, на рынке ИЖК выдел стабильный рост, прерывающийся начавшейся пандемией в 2020 году, однако, перевод в онлайн-сферу многих услуг и создание цифровых сервисов, доступных для людей на самоизоляции позволили выстроить положительную динамику роста.

В связи с этим, Банк России 20 марта 2020 г. принял решение не повышать ключевую ставку, а оставить её на прежнем уровне 6\%. Также ожидается, что на рынке труда возникнут проблемы, связанные с переводом бизнеса в офлайн-режим, что повлечёт за собой снижение доходов населения. Данный фактор повлечет за собой снижение платежеспособности физических и юридических лиц. В связи с ухудшение эпидемиологической ситуации в стране и последствиями пандемии, отразившимися на экономике страны, Банк России принял решение об приостановлении начисления пенни и штрафов по просроченным обязательствам для граждан с положительным ПЦР на наличие вируса COVID-19, находящимся на лечении. Несмотря на поддержку государства и снижение объема обязательств, динамика объема предоставляемых кредитов на 1 июня 2021 года отрицательная. Таким образом, наблюдаемые кризисные явления в экономике будут сдерживать и ограничивать развитие рынка ИЖК в ближайшее время.

Поддержку рынку ИЖК оказывает Правительство РФ. С октября 2018 года существует национальный проект “Жильё и городская среда" который направлен на увеличение уровня доступности жилья первичного и вторичного рынка семьям со средним достатком. Целевые показатели и основные результаты, которые должны быть достигнуты в рамках проекта к 2024 г.:

1) средний уровень процентной ставки по ИК - 7,9\% (2021 г. - 8,5\%);

2) количество предоставленных ИК - 2,26 млн ед. (2021 г. - 1,6 млн ед.);

3) объём выдачи ИК на приобретение жилья на первичном рынке - 1,1 млн ед. (2021 г. - 0,68 млн ед.);

4) повышение индекса качества городской среды на $30 \%$, сокращение в соответствии с этим индексом количества городов с неблагоприятной средой в два раза.

До 2018 года в стране действовала программа поддержки «Жилище», включающая программу поддержки «Молодая семья». К началу 2021 года была принята новая программа поддержки молодых семей (возраст супругов до 36 лет) по ИЖК, подразумевающая компенсацию покупки недвижимости в размере $30 \%$ (семьи без детей) и $35 \%$ (семьи с детьми) от её общей расчетной стоимости.

В 2020 году начали действовать 4 новых программы льготной ипотеки, так, по одной из них ставка для всех граждан РФ составляет 6,5\% годовых. По программе для семей с 2 и более детьми ставка в размере 6\% годовых. Ощутимую поддержку государства получают жители, приобретающие недвижимость в сельской местности, там процентная ставка составляет 3\% годовых. Так же о политике переселения и мотивации для внутренней миграции населения на Дальний Восток (далее - ДВ) свидетельствует программа поддержки семей (по особым условиям) включающая ставку $2 \%$ для приобретения жилья в одном из регионов ДВ.

Экономический кризис, потрясший мир в ходе пандемии, ограничил возможность беспрепятственного кредитования на рынке недвижимости. Программы поддержки, предназначенные для повышения доступности жилья, можно было получить в большинстве известных КО, в которых осуществлялось ипотечное кредитование. Высокая конкуренция между коммерческими банками обуславливает необходимость введения мер, способствующих привлечению новых клиентов. 
Усовершенствование процесса кредитования и автоматизация банковских услуг являются ключевыми факторами в успешном функционировании банковского бизнеса. Возникшая в 2016 году по инициативе Банка России ассоциация ФинТех позволила легализовать инновационные технологии, приступить к внедрению концепций новейших финансовых, предоставить платформу для конструктивного диалога участникам отечественного рынка. На данный момент площадка включает 19 банков, 1 IT-компанию, 3 компании платежных систем и т.д.

Достижение высокого уровня цифровизации, на котором находятся некоторые банки и компании, было получено в ходе внедрения ВMP - систем, где ВРМ (business process management, управление бизнес-процессами). Именно эти системы способствуют адаптации и изменениям процесса оказания услуг с помощью специального программного обеспечения. Концепция подразумевает развитие таких показателей как:

1) Гибкость, т.е. способность компаний быстро реагировать на изменения рынка, оптимизировать затраты и наращивать бизнес-процессы.

2) Скорость, т.е. увеличение продуктивности сотрудников проводится за счет структурированного плана выполнения определенных специальных задач, а также автоматизация рутинных процессов в бизнесе.

3) Качество, т.е. установление и закрепление определенных регламентированных условий стимулирует повышение эффективности труда и улучшение качества результата бизнес-процесса. Снижение ошибок на производстве, возникающих из-за человеческого фактора.

4) Управление, т.е. осуществляется наблюдение за общими бизнеспроцессами, сбор результатов, формирование статистики, показывающей затраты на организацию процесса оказания услуг. Аналитика показывает проблемные зоны.

В настоящий момент рынок очень конкурентоспособен и наибольший успех имеет тот банк, который отвечает запросам клиента. Так, необходимость внедрения системы ВРМ очевидна, если банк ставит перед собой цель сократить время ответа на сообщение от клиента до 5 минут. Или подобрать подходящие под запросы клиента программы кредитования с выгодными условиями.

Однако, переход банков на системы ВРМ является не самым легким процессом. Так, помехой являются высокие затраты на внедрение системы, необходимость постоянных корректировок специалистами, работа которых требуется постоянно. И, хотя выбор большинства компаний падает на описанную выше систему, некоторые банки начинают переводить свой бизнес в другие системы работы, например, системы Low-code, в которых программисты могут разрабатывать программное обеспечение и подбирать оптимальные условия для комфортной работы банковских работников.

Положительная динамика уровня цифровизации прогнозирует скорейший переход ИЖК в онлайн сферу. Вместе с тем ожидается и полная цифровизация предпринимательства, что является удобным и безопасным для населения. Однако, необходимо понимать, что интеграция цифровых систем требует немалых затрат, что может стать преградой для некоторых банков и уменьшить их конкурентоспособность.

$$
* * *
$$

1. Ключевые показатели национального проекта «Жилье и городская среда» и федерального проекта «Ипотека» в его составе. [Электронный ресурс]. - URL: https://www.minstroyrf.gov.ru/upload/iblock/65d/Informatsionnye-materialy-o-natsionalnom-proekte_ZHile_-i-gorodskaya-sreda_.pdf. (Дата посещения: 22.07.2021 г.)

2. Ипотечное жилищное кредитование. [Электронный pecypc]. - URL: https://cbr.ru/statistics/pdko/Mortgage/ML/. (Дата обращения: 23.07.2021 г.)

3. Ассоциация ФинТех. [Электронный ресурс]. - URL: https://www.fintechru.org/about/. (Дата обращения: 23.07.2021 г.) 
4. Молодая семья. [Электронный ресурс]. - URL: http://molodaja-semja.ru/programma-2021/. (Дата обращения: 23.07.2021 г.)

5. Новые виды господдержки в 2020 году. [Электронный pecypc]. - URL: https://www.gosuslugi.ru/help/news/2020_03_03_privileges. (Дата обращения: 23.07.2021 г.)

6. ВPM - системы. [Электронный ресурс]. - URL: https://bpm-systems.ru/bpm-system-about/. (Дата обращения: 24.07.2021 г.)

7. Итоги 2019-го и прогноз на 2020 год на рынке ипотеки: угроза заражения. [Электронный ресурс]. - URL: https://raexpert.ru/researches/banks/ipoteka_2019/\#part1. (Дата обращения: 24.07.2021 г.)

8. ВPM в банковском секторе. [Электронный ресурс]. - URL: https://www.comindware.com/ru/blogbpm-в-банковском-секторе/. (Дата обращения: 24.07.2021 г.)

9. Паспорт национального проекта «Жилье и городская среда». [Электронный pecypc]. - URL: http://static.government.ru/media/files/i3AT3wjDNyEgFywnDrcrnK7Az55RyRuk.pdf. $\quad$ (Дата обращения: 24.07.2021 г.)

\section{Умнов В.А. \\ Анализ тенденций в сельскохозяйственной отрасли России и перспектив ее развития}

Российский государственньй гуманитарный университет (Россия, Москва)

doi: $10.18411 / \mathrm{j}-08-2021-83$

\section{Аннотация}

Рассматриваются основные тенденции развития сельскохозяйственной отрасли России за период с 2005 по 2018 гг. на основе официальных данных Росстат. Проведен анализ изменения производства в отрасли в целом, в том числе с учетом ценовых факторов, а также отдельно по некоторым важным видам продукции. Исследованы тенденции изменения таких важных показателей, как доля добавленной стоимости в продукции, численности занятых и рентабельности отрасли.

Ключевые слова: сельское хозяйство, тенденции развития, производство, добавленная стоимость, численность работников, рентабельность.

\section{Abstract}

The main trends in the development of the agricultural industry in Russia for the period from 2005 to 2018 based on official data from Rosstat are considered. The analysis of changes in production in the industry, also taking into account price factors, as well as separately for some important types of products, is carried out. Trends in the change of such important indicators as the share of value added in production, the number of employees and the profitability of the industry have been investigated.

Keywords: agriculture, development trends, production, value added, number of employees, profitability.

Сельское хозяйство является одной из базовых для экономики страны отраслей. От эффективности производства аграрной продукции зависит не только уровень жизни населения, но и экономическая безопасность страны. С момента перехода к рыночной модели экономики данная отрасль претерпела существенные изменения. Важно проанализировать основные тенденции развития отрасли в целях дальнейшего формирования направлений государственного участия в отрасли и ее поддержки. В этой связи в работе был проведен анализ основных показателей отрасли по данным Росстат за период 2005-2018 гг. [1, 2, 3].

За период с 2005 по 2018 годы объем производства различных видов сельскохозяйственной продукции менялся по-разному, некоторые наименования в абсолютном значении выросли, другие - снизились. Производство скота и птицы выросло в 3 раза, производство зерна - в 1,5 раза, овощей - в 1,2 раза. Производство 